\title{
MODERNISATION OF a BREATHING SIMULATOR HOIST. PaRT 1
}

Zbigniew Talaśka, Bartłomiej Jakus

Naval Academy, Department of Underwater Works Technology in Gdynia, Poland

\section{ABSTRACT}

This article presents the process of modernisation of a car lift in order to adjust it to the function of a hoist for lifting the decompression chamber cover in a breathing simulator used in the Department of Underwater Work Technology of the Naval Academy in Gdynia. Keywords: breathing simulators, equipment of breathing simulators.

ARTICLE INFO

PolHypRes 2018 Vol. 64 Issue 3 pp. 7 - 24

ISSN: $1734-7009$ elSSN: 2084-0535

DOI: $10.2478 /$ phr-2018-0015

Pages: 18 , figures: 7 , tables: 0

page www of the periodical: www.phr.net.pl

Publisher

Polish Hyperbaric Medicine and Technology Society

\section{Original article}

Submission date: $13.06 .2018 \mathrm{r}$. Acceptance for print: 25.07.2018 r. 


\section{INTRODUCTION}

Each time a specific technical object is put into service, it is necessary to carry out tests that confirm their technical and operational parameters conform with the required standards. Particularly important are those constructions which, due to the specificity of their operation, pose a direct threat to human health and life. Such equipment includes diving breathing apparatuses and related devices.

In accordance with PN-EN 250 [1] and PN-EN 14143 [2] standards, breathing apparatuses should be tested under conditions that are as representative as possible of the actual diver's environment. This means that the tests must be carried out in an aquatic environment, at the required pressure corresponding to a specific depth in the water, and simulated breathing of volumes whose values are imposed by the provisions of said standards.

On the basis of the above requirements, the Department of Underwater Works Technology (ZTPP) designed and built a test stand which functioned as a breathing simulator. In terms of its design, it is primarily a decompression chamber (pressure vessel) with a breathing simulator (respiratory pump) adapted to produce an overpressure of up to $2 \mathrm{MPa}$, which corresponds to a depth of $200 \mathrm{mH} 20$. Since there are diving breathing apparatuses of different purposes and sizes, there was a need to adjust the size of the decompression chamber to the largest of them.

Fig. 1 shows a comparison of the size of different diving breathing apparatuses, whose dimensions were taken into account in the process of designing the decompression chamber.

Test procedures for compliance with standard PN-EN 14143 [2] also require the use of a human substitute in the form of a manikin. This requirement is included in section 5.6.1.4. of the standard. The purpose is to reproduce the different human positions in water for which measurements of breathing apparatuses with a semi-closed and closed breathing gas circuit are performed. Thus, inter alia, the size of the apparatus and the need to use a manikin or semi manikin during the tests influenced the size of the decompression chamber.

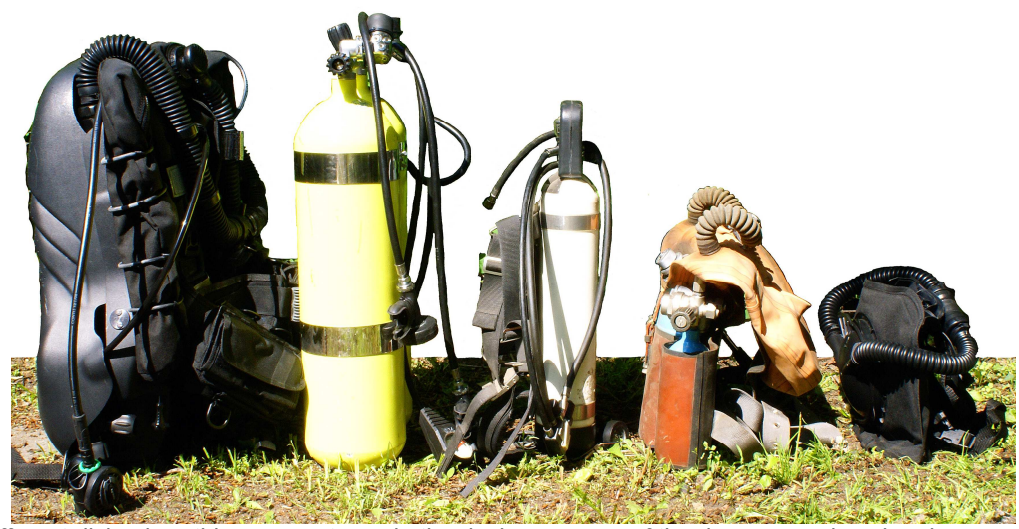

Fig. 1 The comparison of sizes of different diving breathing apparatuses in the design process of the decompression chamber.

Another element that must be taken into account in the construction of the decompression chamber is the required immersion of the breathing apparatus in water.

It should be such that the height from the water surface to the highest component of the apparatus located in the test space is not less than $200 \mathrm{~mm}$. This volume is necessary to exclude the surface effects. The requirement is formulated in section 6.7.1. 6.7.1 of PN-EN 250:2014 [1] specifying the value of immersion and in point 6.3 .1 of
PN-EN 14143:2013 [2], where the problem is only indicated.

Fig. 2 shows the different placement of the diving breathing apparatus of the largest size in the designed decompression chamber, taking into account the exclusion of surface effects (studio drawing).

Fig. 3 shows how to set up a half-manikin with a diving breathing apparatus of the largest dimensions in different positions (studio drawing). 


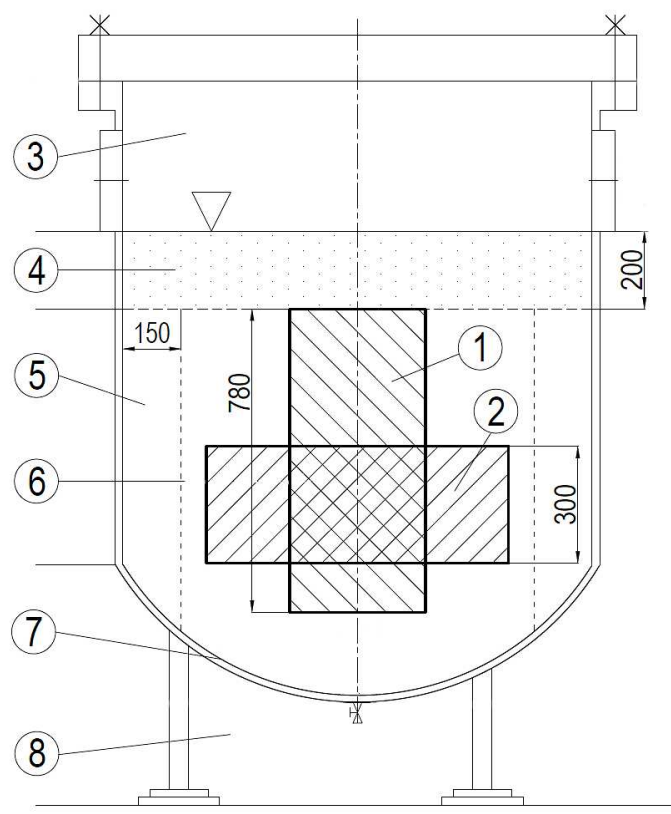

Fig. 2 The different placement of the largest diving breathing apparatus in the designed decompression chamber, taking into account the exclusion of the impact of surface effects (study drawing), 1 - apparatus in vertical position; 2 - apparatus in horizontal position; 3 - air cushion zone and air supply crossings; 4 - Minimum water level above the apparatus; 5 - contro area; 6 - control volume; 7 - bottom of decompression chamber; 8 - situation of the chamber and maintenance area.

As a result of taking into account all the requirements set out in the standards, the necessary space allowing for proper use and important rules for the creation of technical structures, a decompression chamber was designed and constructed. A necessary element of this equipment was the chamber's closing cover. It was designed as a flat plate placed on the upper flange of the chamber and closed with a catch ring blocked on screws located on its perimeter.

The required strength due to the working pressure, as well as the material from which it was made, resulted in the weight of the cover, together with the planned maximum measuring equipment and the apparatus underneath it, being approximately 1,400 kg.

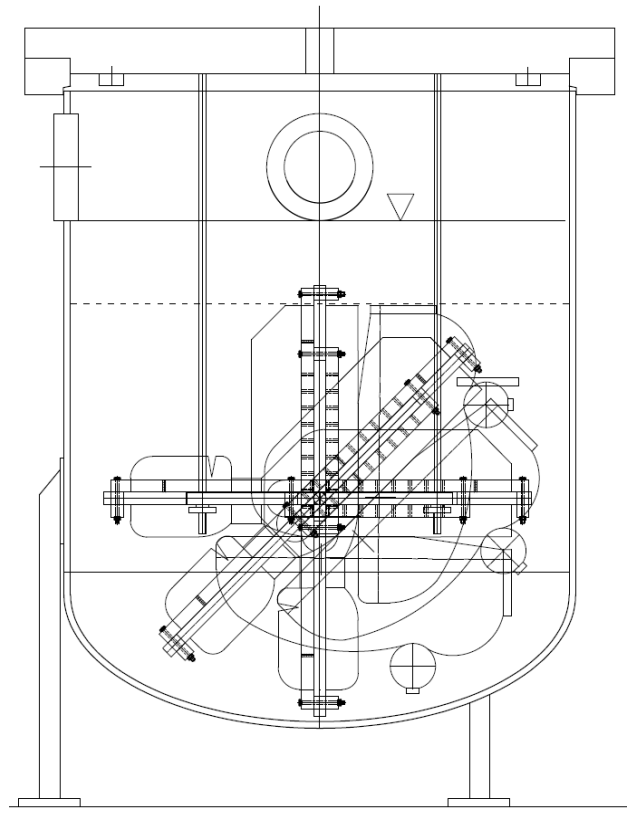

Fig. 3 The different positioning of the half-manikin wearing a diving breathing apparatus of the largest size (study drawing).

The problem which arose was how precisely could the cover be lifted and lowered. In addition, the height of the tank placed on three supports exceeded the height of an average man, i.e. about $180 \mathrm{~cm}$. This fact necessitated the development of a solution that would allow good access to the interior of the decompression chamber and its full use.

Fig. 4a shows an actual comparison of tank height to human height, and Fig. $4 \mathrm{~b}$ shows the required heights that would allow good access to the interior of the chamber.

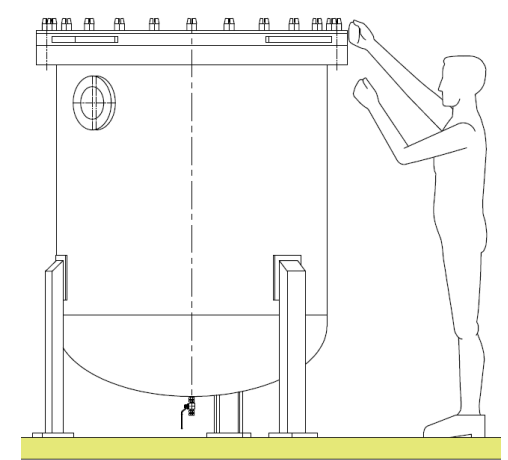

b

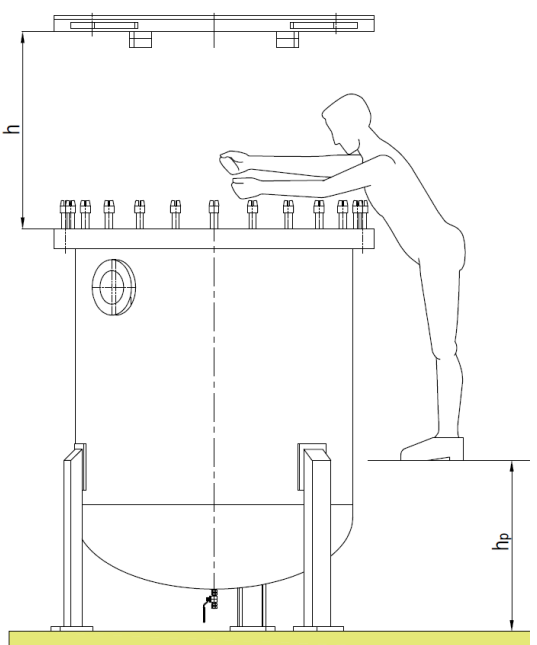

Fig. 4 The proportion of decompression chamber height to human height (studio drawings): a) actual chamber height, b) required height to allow good access to the inside of the chamber. 


\section{MEANS TO ACHIEVE THE OBJECTIVE}

In order to find a solution appropriate to the problem and to design a specific lifting system for the decompression chamber plate, the available literature, technical and user parameters of typical constructional solutions, availability of systems and elements enabling relatively precise lifting of loads in a stationary system, as well as the costs of purchase and manufacture of this type of device were analysed. The conclusions indicated that it is possible to purchase dedicated, precisely functioning lifting systems tailored to individual orders, both from domestic and foreign manufacturers. However, their cost oscillated between several dozen and several hundred thousand zlotys. With a predefined budget, it was impossible to make the purchase.

In the end, attention was drawn to a stationary lifting device used in a mass scale in car repair shops. It was a typical two-column jack with a lifting capacity of at least 2 tonnes and a lift height of approx. $2 \mathrm{~m}$ in relation to the ground. The market cost of purchasing such a device was within the available budget.

A preliminary analysis of the construction of the jack showed that it can be successfully used for the purpose in question. In order to use the equipment, certain structural elements of the equipment had to be modified so that it could be adapted to the operating conditions of the breathing simulator.

Fig. 5 shows a typical two-post car lift, whereas Fig. 6 demonstrates its basic technical dimensions for standard use. [12].

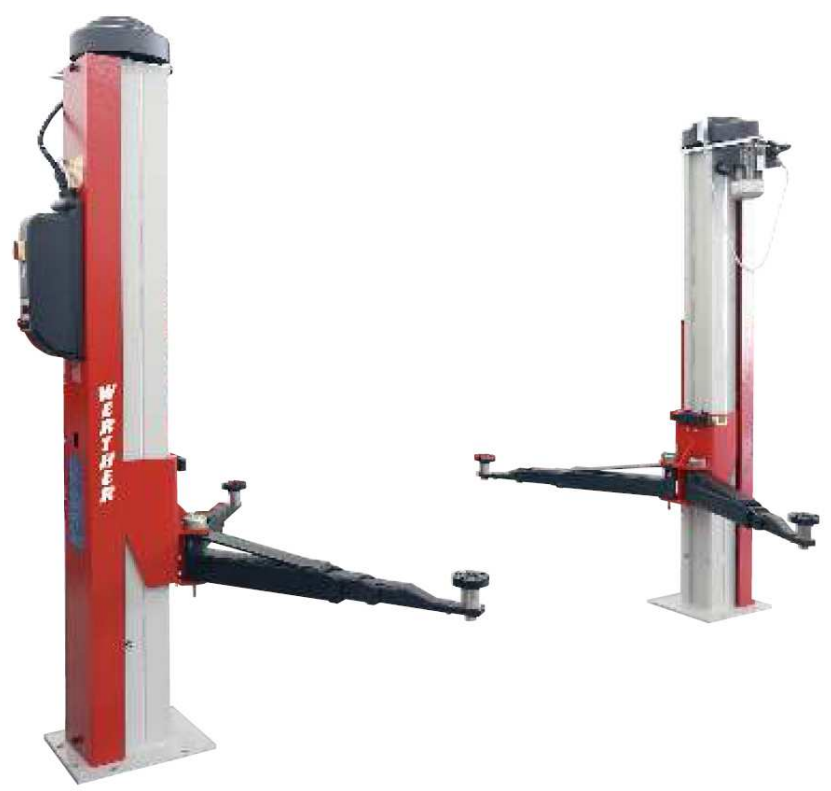

Fig. 5 Werther's two-post lift 254 S [12]

a)

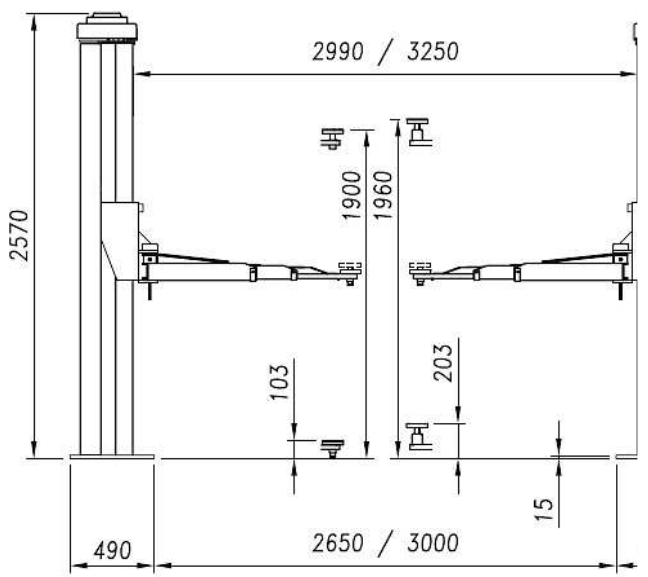

b)

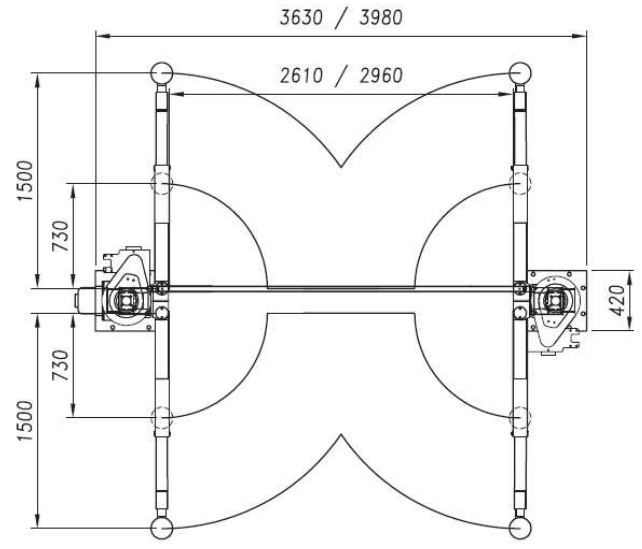

Fig. 6 Basic technical dimensions of a car lift for standard applications [13]. 
A thorough design analysis of all lift components indicated that in order to match the device to the operating conditions of the breathing simulator, the following elements should be subject to modification:

a) the arms connected to a post-mounted cradle require shortening,

b) the distance between posts should be reduced,

c) the placement of posts with regard to the ground requires their elevation with the use of a pedestal,

d) the electro-electronic system for lifting and lowering the claws of the lift require computer control, as well as precise execution of the connection of the cover to the ring of the decompression chamber, e) lift operation safety systems should be equipped with additional protection systems.

Fig. 7 shows the idea of adapting the lift with lifting height ranges, whereas Fig. 8 shows two possible variants of positioning the lift in relation to the decompression chamber of the breathing simulator station.

Taking into account the possibilities and conditions of premises available in the Department of Underwater Work Technology, it was decided that the adjustment of the vehicle lift for the purpose of lifting the decompression chamber cover should be carried out by placing it in the ground recess - fig. 8, variant b).

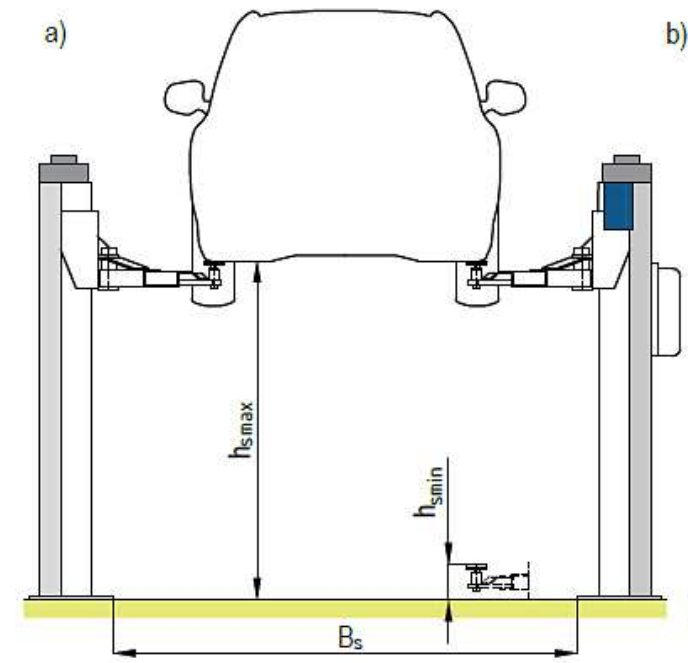

b)

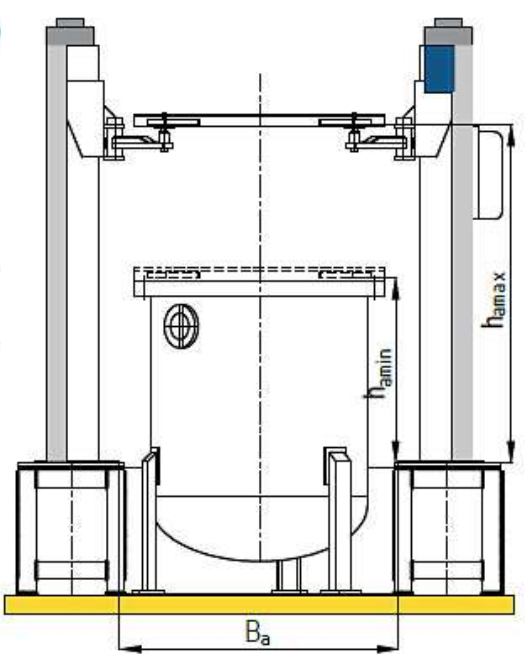

Fig. 7 General idea of adopting a car lift for the purpose of lifting the cover of the decompression chamber with specified lifting height ranges, a) the lift used for the intended purpose, b) the lift after being adapted to fulfil a new function.
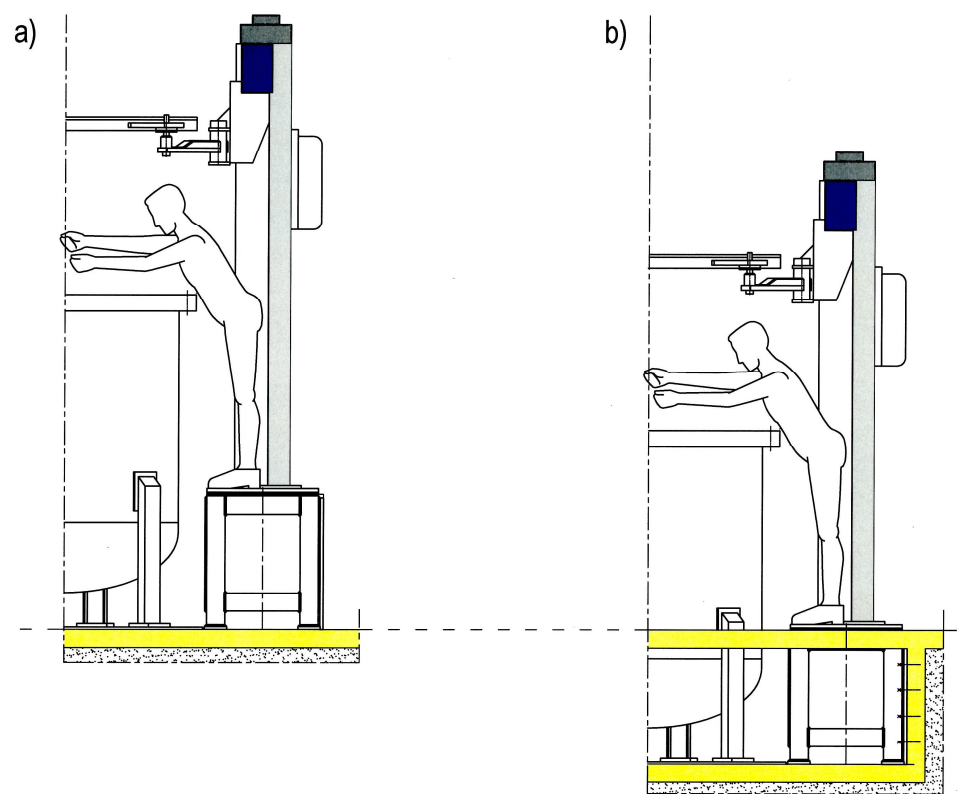

Fig. 8 Positioning variants of the vehicle lift for lifting the cover of the decompression chamber of the breathing simulator, a) positioning of the lift on a flat ground, b) positioning of the lift in the ground recess. 


\section{MODIFICATION PURSUANT TO EUROPEAN LEGISLATION}

Lifting machines, which include vehicle service lifts, are directly covered by the Machinery Directive $2006 / 42 / E C$ [3], which is one of the two individual directives of the Framework Directive 89/391/EEC. They are listed in point 16 of Annex IV to the Directive "Categories of machinery to which one of the procedures set out in Article 12(3) and (4) applies". The interpretation in the guide [5] states that: "Vehicle handling lifts are stationary, mobile or portable jacks intended for lifting whole vehicles from the ground to inspect the vehicle and work on or under the vehicle while it is above the ground... . Among the lifts covered by paragraph 16 are machines intended for the servicing of vehicles, such as cars, motorcycles...".

The provision in point (18) of the Directive indicates that: "This Directive defines only the essential health and safety requirements of general application, supplemented by a number of more specific requirements for certain categories of machinery...".

The consequence of this provision is that, according to the content of the Directive, the machinery listed in Annex IV must absolutely comply with the socalled essential requirements. It is a set of general rules of conduct according to which the requirements in question must be fulfilled from the technical and formal perspective in order for the machine to be placed on the Community market for trade in goods or for use [9]. The specific requirements set out in the Directive are harmonised standards with the Directive. These are instructional documents closely related to the EU directives. They contain detailed recommendations on how to demonstrate the conformity of a particular product with one or more requirements imposed by a particular directive. They support the directives, but do not have to be applied on a mandatory basis. It is generally accepted that fulfilment of the requirements of harmonised standards gives rise to a presumption of conformity with the requirements of the Directive in the fields covered by the standards. Demonstrating that a product is in conformity with a given harmonised standard is the simplest and most effective method of demonstrating compliance with the essential requirements of the Directive.

In practice, this means that new machinery has to undergo a full certification procedure before it can be put into service. The responsibility for carrying this out is primarily borne by the manufacturers of the machinery and their authorised representatives - Articles 20 and 23 of the Directive [3]. According to Article 21, new machinery authorised to be placed on the market must bear the CE mark. It is intended to ensure that the machinery fully complies with the requirements of the Directive.

The Machinery Directive is primarily addressed to machine manufacturers and their representatives, as well as suppliers and distributors. It is the basis for shaping the level of safety in the operation of machinery. This is due to the fact that compliance with the provisions of the Directive ensures that the level of tolerable risk posed by machines is achieved, which allows them to be consciously accepted by designers and manufacturers, and later by users. The basic principle is that machinery should be designed in such a way that it is safe in itself. This means eliminating or reducing risks as far as possible at the design stage. The designs created should be as inherently safe as possible.

The second individual directive of the Framework Directive 89/391/EEC is the Tool Directive 2009/104/EC [4]. It formulates the minimum requirements to be met by the employer when equipping employees with the means of work, including machinery and equipment necessary to perform the specified tasks. As stated in Article 1(1) of the Directive: "...lays down minimum health and safety requirements for the use of work equipment by workers during their work..." [4]. Thus, it is entirely and exclusively the responsibility of the employer to ensure safety during operation, including in particular the use of new and/or 'old' machinery. This requirement means that the user must take care of the machine in such a way that the level of safety is not reduced by carrying out specific maintenance and operation. Through these operations, the machinery must thus meet the health and safety requirements corresponding to the moment it is placed on the market and/or put into service. This Directive should be seen as a supplement to the Machinery Directive.

Very important from the point of view of introducing any changes to new machinery is the entry in Annex II of the Machinery Directive [3] in point 1A "EC declaration of conformity for machinery" indicating that: "...This declaration refers only to machinery in the condition in which it was marketed and does not include components added by the end user or his subsequent operations..." [3].

This provision implies a number of important procedures to be followed in cases where the machine undergoes transformations (alterations, changes, conversions), both in the technical and organisational sense. As a result of regular wear and tear of machines over time, technical aging and a number of other processes that decrease the maintenance of technicalutility parameters, it is a natural phenomenon, especially among users, to attempt to prevent them. Through the processes of repair, modernisation, upgrading, retrofitting, etc., the owners of machines wish to extend the time of their effective operation without incurring excessive costs associated with the replacement of the machine with a new one. Typical reasons for introducing changes to machines include:

a) the need to adapt the machine to new production and technological needs,

b) an obsolete structure but not such as to render it out of service,

c) the need to repair damage through repairs and the need to use new parts,

d) no access to spare parts of the same type and manufacturer,

e) inspection, maintenance, diagnosis and decisions to make changes,

f) improvement of the quality and performance of machinery,

g) extension of the scope of applications,

h) the need to comply with minimum requirements,

i) ensuring a higher level of safety.

Most of the reasons listed above require alterations in the construction of the machine, technical parameters, the use of other equipment, materials, etc. 
Usually, the improvement and/or restoration of the functional qualities of the machine is connected with performing conversions (changes) directly in the machine. This is referred to in the Machinery Directive [3] as "modification"1. It should be stressed that the concept of "modernisation" does not occur in the Directive. However, in the Tools Directive the word "modernisation" is contained in Article 2 - Definitions in point b) and in Article 6 - Work equipment posing a particular risk in point $b$ ).

Both directives do not specify the meaning of the concepts of modification and modernisation. The lack of unambiguous definitions, and the associated systematised terminology, leads to misunderstandings and divergent interpretations of the provisions. This is particularly important when the user initiates the process of machine modification. This is due to the fact that different degrees of change in the machine result in different levels of technical intervention in the machine. This has a direct impact on determining whether the changes made to the machine are unimportant or significant.

Such an evaluation determines whether the modification has already led to the creation of a new machine or whether it still complies with the requirements of the directive for the machine placed on the market by the manufacturer. Thus, a very fundamental question arises: how deeply may interference in the processes of modification reach for the machine to be considered as being in conformity with the minimum requirements of the Machinery Directive, or when a new machine is created which also needs to meet the essential requirements of the Machinery Directive? Unfortunately, directives [3], [4], like the guide of the European Commission [5] do not provide answers to these questions. The inadequate or incorrect indication of essential requirements in the Machinery Directive makes it necessary to apply other technical specifications or to develop solutions according to general engineering or scientific knowledge [17].

The analysis of publications related to the topic indicates that the modification of the machine may be carried out in one of two directions:

a) where the changes made to the machinery do not constitute a substantial modification,

b) where the changes made to the machinery constitute a substantial modification.

In the first case, the owner of the machine does not implement changes that would lead to the creation of a new machine. This means that the user does not assume the obligations of the manufacturer. The machine does not lose the validity of the CE marking and the owner does not have to undergo a full procedure to confirm the essential requirements. However, it is the owner's responsibility to carry out a procedure to check that the machine meets the minimum requirements of the Tools Directive in terms of health and safety of workers' use of work equipment at work. It is generally accepted that a modification consisting of:

- the replacement of essential components of the machinery with the same ones,

- the use of components having the same function and level of safety,

- retrofitting the machinery with additional safety devices to increase the level of safety during use,

- not changing the functionality of the technical object, is not considered as the creation of a new machine (new product).
In the second case, the owner makes such significant modifications that result in the construction of a new machine. The changes carried out are so deep that the substance of the machine does not meet the basic requirements obtained by the first manufacturer as of the date of placing it on the market (use), as described in point (18) of the Machinery Directive [3]. The machine loses the validity of the original CE marking and at this point the user becomes the "second" manufacturer of the machine. The consequence of this is that the owner-new manufacturer must again comply with the requirements of Article 5(1) of the Directive. This means the implementation of a tedious process of re-obtaining the CE mark, which involves the following procedures [17]:

- ensuring that the machinery complies with the relevant essential requirements of health protection and safety as defined in Annex I of the Directive;

- ensuring that the technical documentation referred to in Annex VII, Part A of the Directive is available;

- provision, in particular, of the necessary information such as operating manuals;

- $\quad$ carrying out the relevant conformity assessment procedures under Article 12 of the Directive;

- drawing up the EC declaration of conformity on the basis of Annex II, Part 1, Section A and ensuring that it is attached to the machinery;

- provision of the CE marking in accordance with Article 16 of the Directive.

The Directive does not explain what is meant by the term 'substantial modification' which results in the creation of a new machine and how much one needs to intervene in the construction of a machine in order to become its new manufacturer

\section{THE PROBLEM OF MODERNISATION IN POLISH LEGISLATION}

All requirements of European directives have been implemented into Polish law. The general principles of occupational safety formulated in the framework directive are incorporated in the Polish Labour Code. More detailed requirements corresponding to European directives are contained in the following legal acts.

- Machinery Directive 2006/42/EC - The Regulation of the Minister of Economy, Labour and Social Policy of 21 October 2008 on essential requirements for machinery and safety components - Journal of Laws No. 199 item 1228;

- Tools Directive 2009/104/EC - The Regulation of the Minister of Economy of 30 October 2002 on minimum requirements for health and safety at work with regard to the use of machinery by employees at work - Journal of Laws No. 191, item 1596 of 18 November 2002.

The basic legal act regulating the issues related to the introduction to the market and subsequent operation of certain types of machines is the Act on technical supervision [6]. It is an important document, inter alia, from the point of view of introducing modifications to machines. On the basis of Article 5 (2) of the Act, a regulation on types of technical equipment subject to technical supervision was introduced [7]. In Sec. 1 point. 6e) lifts (hoists) are listed as close transport 
equipment (CTE) subject to technical supervision by the Office of Technical Inspection. On the basis of the same act, art. $50 \mathrm{sec}$. 2, lifts are also subject to the Military Technical Inspection. For this group of devices, a regulation has been issued on the technical conditions to be met by hoists [8]. Section 1 - General provisions of Sec. 2 point 10 of the Regulation states the following: "car lifts - fixed hoists for lifting and lowering motor vehicles".

The content of the Regulation clearly indicates that any changes in the design and operating parameters of the machine (device) must be approved by the UDT or WDT. The whole process of making changes along with its documentation and putting the machine into service is supervised by the indicated institutions.

In Polish legal acts, the basic word "modernisation" is used. The analysis of professional literature and publications indicates that this term is not an unambiguous concept. Depending on the source of information about the said term has the following definitions:

- $\quad$ Acc. to Wikipedia [22]:

"Modernisation - modernisation, product upgrading, permanent improvement...; Modernisation denotes modernisation of fixed assets in order to increase their usable value";

- $\quad$ Acc. to Universal Encyclopaedia, PWN 1985:

"Modernisation [franc.] in business, a term meaning the improvement of the used machines and production equipment by introducing changes in their construction...";

- Acc. to the definition used by the Office of Technical Supervision [23]:

"Modernisation is a change in the construction, materials used or technical parameters of a device ..., as compared to those originally set, however without significant changes in the characteristics or designation of the device, as compared to those originally set";

- Acc. to the definition proposed in the Regulation of the Minister of National Defence - Journal of Laws of 01.12.2014, it. 1678 - Sec. 2 pt. 8) [9]:

"Modernisation of a device - making changes in the operational parameters or design of the device in relation to the original state, affecting the safety of operation of the device".

- Acc. to the definition contained in the marine technology property management manual [11]: "Modernisation - a process of modernisation of military equipment consisting in the change of its usable and operational parameters, including in particular critical parameters. The result of modernisation is new military equipment".

- $\quad$ Acc. to presentation [12]:

"Modernisation - a set of organisational-technical activities changing the construction or technical parameters of a technical device in relation to those originally set out in the technical documentation of the device, aimed exclusively at maintaining or upgrading the level of safety in using the device, which are not treated as producing a new device".

The word "modernisation" also has about a hundred synonyms with different scope of meaning. For groups of meanings such as: renewal of something, improvement and modernisation of something, repair of something, improvement of the operation and functioning of something, the following words are most frequently used: improvement, retrofitting, upgrading, enhancement, regeneration, repair, renewal, modification, and many others.

A relatively broad set of words that can be used reflects the scope of their application to describe different procedures for carrying out modernisation. This means that by using them it is possible to describe the materially different scopes of changes being introduced. Each of them in a different way expresses the reason for the modernisation due to the existing situation, and thus indicates the course of action. Depending on the intended purpose, it may be said that [17]:

- the alteration of the machine may result in its adaptation to new technical and operational requirements of the safety regulations in force at the time, or

- the refurbishment of machinery, which often requires the replacement of components with newer ones, may lead to an increase in its utility value, or

- adaptation as an adjustment, alteration of the machine without changing the way in which it is used can change and/or increase its functionality in order to obtain additional performance characteristics and thus allow it to be used for purposes other than before, or

- conversion is most often a change of the existing condition of a machine to another one, resulting, for example, in adaptation to the new technical and operational conditions of its owner.

Referring to the national legislation in force, all of the above possibilities, as well as a number of other ones, need to be implemented in a process known as modernisation. Therefore, the need for introducing changes to the machine should be considered on a caseby-case basis, taking into account the specific conditions of each instance.

According to the authors, for the problem presented in the article, a more precise description would be to use the words: "performing modifications to the machine in order to adapt it to the new function, and thus extending its functionality with new usability options". In this context, adaptation would mean adapting (reshaping, altering) a car lift for the purpose of lifting a different type of weight as compared to the standard use.

A separate issue is how the concept of modernisation, applied in Polish law, relates to the concept of modification applied in European directives? Can both words be used interchangeably? Is it possible to treat both concepts as equivalent, or is there a specific relationship between them? If so, to what extent does the meaning of the two words differ?

During the analysis of the literature, the authors encountered different formulations, explanations, interpretations, etc., where the words "modification" and "modernisation" were used alternately, sometimes contrary to the presented content. Nevertheless, a very cautious conclusion could be drawn that the concept of modernisation is a concept that covers a broader activity than modification. It may also be concluded that a series of modifications lead to modernisation. However, this is too far-reaching an interpretation, which unfortunately does not have an unambiguous confirmation in the literature. On the other hand, it is certain that the term "modification" should be used when using the content of directives, whereas under Polish law the term "modernisation" should be used. 
The above considerations indicate that there is also a lack of clear and transparent interpretation of the provisions introducing both directives into our legislation.

THE IMPACT OF THE PROVISIONS OF DIRECTIVES AND POLISH LEGAL REGULATIONS ON THE PROCEDURES FOR RETROFITTING A CAR LIFT FOR USE LIFTING THE BREATHING SIMULATOR

Taking into account the problem of machine modernisation as a whole, it can be clearly seen that:

- among users and manufacturers there is insufficient knowledge of the content of directives: the machinery and tools directives, as well as regulations introduced on their basis into Polish law; thus, there is little awareness of the principles regarding, for instance, carrying out modernisation;

- there is a lack of systematic and unambiguous terminology in legislation, the use of which is an essential condition for proper understanding and observance of the principles of carrying out various activities related to changes made to machines, e.g. modernisation; According to the author of the publication [17], when referring to specific regulations, methods of action, interpretations and a number of other documents it is necessary to "speak the same language". This can guarantee a proper, uniform and professional approach to the issues in question;

- $\quad$ there are no uniform, simple and legible criteria for making changes to machinery;

- the boundaries between a 'substantial' and 'minor' modification/modernisation are not clearly defined in either European or Polish law and in many other documents; conditions are not presented as to how profound the modifications cause the machine to become a new device.

Therefore, it should be assumed that neither EU nor Polish legislation has managed to cope with the problem of defining the "depth" limit of changes made to the machine. For this reason, the scope of interference in the construction of machines in the directives depends practically on the level of safety of their operation (tool directive). It was assumed that any modification (modernisation) which will deteriorate the safety conditions of a machine's operation is considered to be significant. In the case of modernisation where the level of safety is not reduced or increased, it can be considered as minor, insignificant. The literature indicates that even farreaching changes from the point of view of maintenance of safety of use do not result in the loss of the CE mark.

This is due to the fact that modification is not only a change in the construction of the machine [15] but it also involves the disassembly of certain machine parts, as well as the use of newer solutions that do not result in the loss of its functionality. At this point a further question arises as to what should be understood by the concept of functionality of the machine, or rather its functions. As defined and explained in Wikipedia [23]: "A function is the property of an object, device associated with its use, purpose or task...."
The most general and concise definition of function proposed by A. M. Gadomski (1986) is as follows: "function is the property of a process or system necessary to accomplish its goal, i.e. what it was designed for or what it is used for". This definition implies that the same function can be performed by various physical processes or systems... . The device "performs its function" if it is currently operating according to its purpose. The device is "functional" if it is ready for operation in accordance with its intended use.

Referring the above definition of the concept of the primary function of the device - the lift prior to modernisation to the situation after modernisation, one should pose a question whether the replacement of the weight of the lifted and lowered technical object (car) with the weight of the lifted tank cover will be in fact a significant change in its function. Will the form (shape) of the lifted mass in a spatially convergent system indeed imply a complete change of its intended use? The analysed literature does not provide an unambiguous answer to these questions.

In the authors' opinion, the machine's lifting and lowering function should not be significantly changed despite the fact that the intention of modernisation is to modify the type and shape of the lifted weight. In fact, the lift will retain its functionality while being upgraded with a new function and will continue to lift a certain load in a slightly altered way.

When commencing the process of modernisation of a particular machine, including the said car lift, in accordance with Polish legislation implemented procedures are required to encompass the following elements:

- for all machines (technical devices) subject to technical supervision, in which the user (manufacturer) decided to introduce changes, their scope must be agreed with the UDT (WDT);

- if possible, the scope of changes to the machine should be agreed with the machine manufacturer and approved or the manufacturer should at least be informed about them, and supplied with a full set of documents from the modernisation process [14];

- preparation of documentation (a report) on the changes that the user wishes to make;

- analysis in as much detail as possible of the changes made to the design and functioning of the machine in a comprehensible manner and based on clear criteria;

- analysis and assessment of risks from the point of view of safe use of the machinery, showing whether their operational conditions have deteriorated, been maintained or improved by means of standing methods for this purpose, e.g. in accordance with the standard PN-EN ISO 12100;

- $\quad$ preparation of a new instruction manual for the machine, treating it as an update to the original instruction, containing a description of changes made with the instruction of operation of new elements installed in the device.

Every user undertaking modernisation (modification) actions must be aware of the consequences of this process. Most often, the basic aim of this process will be to proceed in a way that does not lead to the 
creation of a new machine. For this reason, individual procedures must be developed and carried out in order not to invalidate the CE mark. It is therefore necessary to seek arguments that clearly demonstrate that the changes made to the machine will not cause deterioration in the maintenance of safety conditions. Under the Labour Code, it is the responsibility of the machine user (owner) to ensure that the machines are as safe as possible.
The next article will analyse the specific changes required in order for a two-post car lift to be used to lift a decompression chamber cover. Based on the results obtained, it will be possible to carry out a risk analysis in order to demonstrate whether the changes introduced will mean that the lift following modification would constitute a new machine or whether it will be able to retain the CE mark assigned to it by the manufacturer.

\section{REFERENCES}

1. Polish standard PN-EN 250:2014 Respiratory equipment. Self-contained open-circuit diving compressed air breathing apparatus for diving Requirements, testing and marking Polish Committee for Standardisation Warsaw 2014;

2. Polish standard PN-EN 14143 Respiratory equipment. Autonomous closed-circuit diving apparatuses Polish Committee for Standardization Warsaw 2013;

3. Directive 2006/42/EC of the European Parliament and of the Council of 17.05 .2006 on machinery, amending Directive 95/16/EC Official Journal of the European Union 09.06.2006;

4. Directive 2009/104/EC of the European Parliament and of the Council of 16 September 2009 concerning the minimum safety and health requirements for the use of work equipment by workers during their working time (second detailed Directive within the meaning of Article 16(1) of Directive 89/391/EEC) Official Journal of the European Union 03.10.2009;

5. Guide to the application of Directive 2006/42/EC on machinery - second edition June 2010 edited by lan Fraser European Commission Enterprise and Industry Ref. Ares (2015) 1075180 - 11/03/2015;

6. Act of 21 December 2000 on technical supervision (Journal of Laws No. 122, item 1321, as amended);

7. Regulation of the Council of Ministers of 7 December 2012 on types of technical equipment subject to technical supervision (Journal of Laws of 27.12.2012, item 1468)

8. Regulation of the Minister of Economy of 28.12.2001 on the technical conditions of technical supervision to be met by lifting devices (Journal of Laws No. 4, item 43);

9. Regulation of the Minister of National Defence of 18 November 2014 on the technical conditions of technical supervision relating to certain specialist pressure equipment and types of equipment whose operation requires special qualifications (Journal of Laws of 01.12.2014, item 1678);

10. Scientific and research work on "Identification of the most frequent causes and sequences of accidents at maintenance and repair of production machines and equipment on the basis of accident analysis", commissioned by the Social Insurance Institution (ZUS) with its registered office in Warsaw by the Centre for Education and Prevention Warsaw 2010;

11. Instruction on the management of property of maritime technology DD/4.22.7/ MON Inspectorate for Armed Forces Support Bydgoszcz 2013;

12. Paweł Urbańczyk "Modernisation of pressure elements of boiler devices with regard to environment protection aspects. National law or assessment of compliance. The $8^{\text {th }}$ Scientific and Technical Conference on Environment Protection in the Energy Sector. Katowice $25-26$ February 2013, Notified body UDT-CERT No. 1433

Websites:

13. Lift advertisement - http://www.wertherint.com/wpcontent/uploads/2012/02/3_62603_170524_Werther_2Post_ SinglePost_MobilePost_06_254S_4_161011.pdf (02.08.2018)

14. Category: Modernizations - https://bezpieczenstwowsystemachsterowania.pl/category/modernizacje/ (09.08.2018)

15. Modernization of a machine by a user. What does a manufacturer say to this? https://bezpieczenstwowsystemachsterowania.pl/2018/02/modernizacja-maszyny-przez-uzytkownika-co-na-to-producent-maszyny/ (09.08.2018)

16. Modernization of a machine - case study - https://bezpieczenstwowsystemachsterowania.pl/2018/01/modernizacja-maszyny-studiumprzypadku/ (09.08.2018)

17. Modernization of a machine - what we should know - https://bezpieczenstwowsystemachsterowania.pl/2018/01/modernizacja-maszyny-copowinnismy-wiedziec/ (09.08.2018)

18. Modernizations, modifications... What is what - https://bezpieczenstwowsystemachsterowania.pl/2016/01/modernizacje-modyfikacje-co-z-czymsie/ (09.08.2018)

19. Polish Language Dictionary of PWN -

https://sjp.pwn.pl/slowniki/modyfikowa\%C4\%87.html (09.09.2018)

20. Polish Language Dictionary -

https://sjp.pl/modyfikowa\%C4\%87 (09.09.2018)

21. Dictionary of the Polish Scientific and Technical Society -

https://pntte.wordpress.com/szkolenia/terminologia-obsługiwanie (09.09.2018)

22. Wikipedia -

https://pl.wikipedia.org/wiki/Modernizacja_(technika)

23. Technical Supervision Office -

https://www.udt.gov.pl/naprawy-i-modernicazje (09.10.2018)

24. Wikipedia -

https://pl.wikipedia.org/wiki/Funkcja_(in\%C5\%BCynieria) (09.10.2018)

dr inż. Zbigniew Talaśka

Akademia Marynarki Wojennej im. Bohaterów Westerplatte

81-103 Gdynia 3 ul. Śmidowicza 69

Zakład Technologii Prac Podwodnych

tel +586262746 fax +586253882

e-mail : zbigniew_talaska@wp.pl 
${ }^{1}$ modification - according to the Dictionary of the Polish language of PWN is a slight change, alteration, improvement of something that does not affect the essential nature of an object [19]; according to the Dictionary of the Polish language, to modify means 1 . to introduce changes, corrections, improvements 2. modify - change, transform partially [20]; according to the dictionary of the Polish Scientific and Technical Society, modification is a set of all technical administrative and management activities aimed at changing the function of the object. 1 . Modification does not imply a change in the object with an appropriate other object. 2. Modification is not a service activity, but consists in changing the function of the object to another one. A modification may affect reliability or performance, or both. 3) Modification may be carried out through a maintenance organisation [21]; according to Annex A - Dictionary of Terms and Definitions - modification is a process of upgrading military equipment, consisting in replacing or refurbishing of existing components, functions or software, without changing its essential purpose. The modification does not result in development of new military equipment [11].; according to presentation [12] - modification is a set of organisational-technical activities performed on a device which result in an alteration of its original characteristics, intended use and/or type and thus the device is to be treated as a new product as defined by the directive. 